Association for Information Systems AIS Electronic Library (AISeL)

Wirtschaftsinformatik Proceedings 2005

Wirtschaftsinformatik

February 2005

\title{
A Procedural Model for the Production of Reusable and Standard-Compliant E-Learning Offerings
}

Claudia Müller

University of Potsdam

Matthias Trier

Technical University Berlin

Follow this and additional works at: http://aisel.aisnet.org/wi2005

\section{Recommended Citation}

Müller, Claudia and Trier, Matthias, "A Procedural Model for the Production of Reusable and Standard-Compliant E-Learning Offerings" (2005). Wirtschaftsinformatik Proceedings 2005. 46.

http://aisel.aisnet.org/wi2005/46

This material is brought to you by the Wirtschaftsinformatik at AIS Electronic Library (AISeL). It has been accepted for inclusion in Wirtschaftsinformatik Proceedings 2005 by an authorized administrator of AIS Electronic Library (AISeL). For more information, please contact elibrary@aisnet.org. 
In: Ferstl, Otto K, u.a. (Hg) 2005. Wirtschaftsinformatik 2005: eEconomy, eGovernment, eSociety; 7. Internationale Tagung Wirtschaftsinformatik 2005. Heidelberg: Physica-Verlag

ISBN: 3-7908-1574-8

(C) Physica-Verlag Heidelberg 2005 


\title{
A Procedural Model for the Production of Reusable and Standard-Compliant E-Learning Offerings
}

\author{
Claudia Müller \\ University of Potsdam \\ Matthias Trier \\ Technical University Berlin
}

\begin{abstract}
Cost-efficient production of high-quality learning contents is an important success factor for a sustainable and economic realisation of E-Learning. This necessitates the design of sustainable production processes, which create reusable Learning Objects and require minimal resources. In such a context, this contribution introduces a practical and business-process oriented Procedural Model for the Production of reusable and standard-compliant E-Learning Offerings. It has been developed and applied in a project that produces learning contents for a Master program of an international virtual university. After the introduction of a reengineering method, a special analysis instrument for E-Learning has been designed to analyse the existing production processes and to improve them in terms of efficiency, costs, standard-compliance, and process automation. The method introduced is hence not focussing on individual technical solutions but on the efficiency of the whole E-Learning production and value chain. It gives an orientation for establishing and maintaining sustainable and competitive E-Learning production processes with appropriate effort.
\end{abstract}

Keywords: E-Learning, Processes, Efficiency, Process Automation, XML, Content, Standardisation

\section{Motivation}

In the years 2000 to 2004, the German Federal Ministry for Education and Research established a funding program called 'New Media in Education'. With a budget of about 200 million Euro, this initiative supported a multitude of projects within the German sector of higher education [Bmbf00]. The primary objective was a continuous and wide integration of new media for teaching, learning, working, and communication in university education and improved media support for education offerings. 
The large amount of projects supported, reflects the optimistic perception of these years. For example, a study of Berlecon Research in 2001 [Saut02] estimated, that the education budget of German enterprises will increase by 600 percent from 330 million Euro in 2001 to 2 billion Euro in 2005. But already in the year 2004, this euphoria was lost. In April 2004, the Federal Ministry of Economics and Labour ordered a study called 'Monitoring Information Society' [Gra+04], which found that experts have lost confidence in the expansion of E-Learning services in the information economy.

This development also seems to have affected publicly financed E-Learning projects. Once the initial funding period ended, they often lacked concepts for ensuring the appropriate revenues, which are necessary to compensate the high initial investments and the costs of actually running the structures and processes [HaHo04].

This implies that the sustainability of current, often very proprietary constructed structures and processes of such E-Learning projects should be reassessed. Sustainability is here defined as the succession and continuous development of projects together with their implemented processes, created learning units, existing experiences of the authors and editors and the employed tools [Deg03, HaHo04].

Being one of the initiatives within this BMBF-Program, the project 'MBI- International Master of Business Informatics' also faced these challenges. One major objective was hence the establishment of a private and internationally oriented E-Learning corporation until the end of the funding period. By now, the resulting Virtual Global University (VGU) has affiliations in India, Taiwan, Nepal, Pakistan, Slovenia and other parts of Eastern Europe and Asia [VGU04].

The Department of Systems Analysis and IT of the Technical University Berlin is participating in this virtual university since 2001. Next to 16 further German, Swiss, and Austrian Chairs of Business Informatics, it develops and offers the learning modules Knowledge Management (KM) and Process Modelling (PM).

To be able to offer professional products in the competitive E-Learning market, it became necessary to fundamentally analyse and reengineer the existing course offerings. The main objective was a sustainable production process, which is capable of producing reusable Learning Objects and simultaneously is requiring a minimum of resources.

To achieve this objective, a comprehensive reengineering project for the modules' production processes was launched in 2003 to assess and improve the existing procedures. It has been segregated into the following five project phases:

1. Capturing and modelling all existing E-Learning production processes,

2. Evaluation of existing E-Learning production processes using a special analysis instrument for E-Learning process evaluation,

3. Identification of the main potentials and development of a concept, 
4. Realisation of the main improvements and documentation of the final E-Learning process, and

5. Comparison and measurement of the old and the new processes to substantiate and quantify the improvements in efficiency.

The execution of this reengineering project and the resulting challenges for the development of a standard-compliant and partially automated E-Learning production process are introduced in the next sections (see figure 1). During this initiative, the practical experiences have continuously been documented and refined in order to create a generic procedural model for the Production of reusable and standard-compliant E-Learning Offerings (PELO-Model). This model is explained in great detail in section 4 . The last section illustrates the approaches of measuring the efficiency gains and cost savings of the reengineering project.

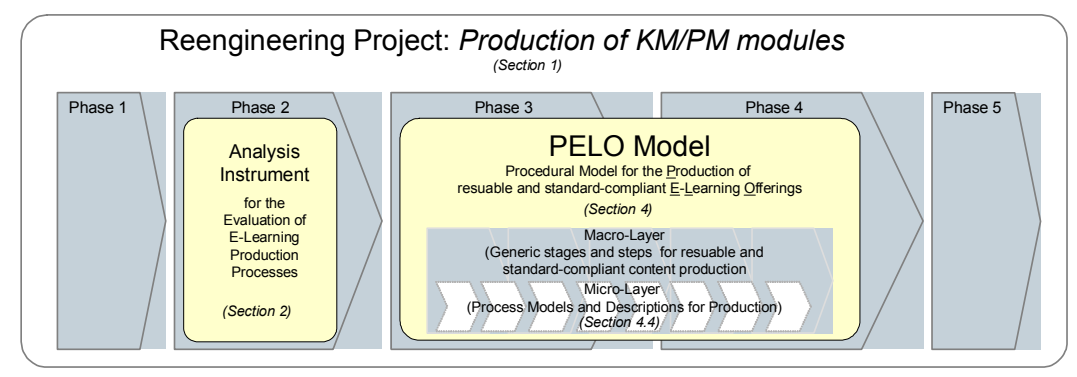

Figure 1: Overview about the article

\section{Analysis Criteria for Developing a Sustainable Production Process}

The cost efficient production of high-quality learning contents is an important success factor for economic E-Learning offerings [ $\left.\mathrm{Kra}^{+} 03\right]$. With this perspective, the existing processes for content-oriented and technical development of Learning Objects for the course offerings Knowledge Management (KM) and Process Modelling (PM) have been analysed. In phase one of the reengineering project, the existing procedures have been captured and modelled with Event-driven Process Chains (EPC).

In the succeeding identification of potentials (phase two), a special analysis tool has been developed, which assembles the most important efficiency criteria for E-Learning production processes. It is based on the concept of Critical Success Factors, which assumes, that a process's success is largely attributable to only a few factors [Oest95, pp. 108]. These specific factors consist of critical success factors for the overall E-Learning offering, general success factors of processes, 
and special process-specific success factors for the E-Learning production process. Together, these three segments constitute categories of requirements to evaluate the existing E-Learning production processes.

The requirements category of critical success factors for the overall E-Learning offering includes the definition of learning contents and media, the selection of the Learning Management System and the Learning Environment, the realisation of a business model, and the reusability of learning contents. The next section contains general success criteria of processes like process duration, costs of production, quality of the output, measurability of the process, and flexibility to change the process structures.

The last section with individual and process-specific success criteria finally lists items like reduction of complexity ${ }^{1}$, reduction of employed file formats for identical contents ${ }^{2}$, increased transparency about the process's status, or standardised versioning. These criteria have been derived from the existing production processes. For every criterion a description is available to help evaluating the actual process. For example, the reduction of content-related redundancies checks, if the same contents are not stored in different file formats (like MS PowerPoint and MS Word).

These criteria can also be related to different working areas and scopes, depending on the actual scope of the success factor. To evaluate the need for improving the existing processes, a scale reaching from 1 for low priority up to 3 for high priority has been applied. The evaluation was based on how the actual processes fulfilled the various criteria. A further issue was the decision, if these criteria own an important potential for improvement or should be worked on later.

Next to the establishment of new successful processes, the criteria catalogue enables a comprehensive evaluation and comparison of existing processes using specified categories. Further, implemented procedural improvements can be better measured against the original process. Table 1 shows an excerpt of the completed evaluation sheet for the production processes of the modules KM and PM.

In the process example described, the reduction of complexity is focussing on structural and procedural aspects of the production, e.g. reduction of process steps and reduction of interdependencies within the processes.

2 In principle, the course Knowledge Management and Process Modelling are comprised of audio-, video- and text-based content objects. 


\begin{tabular}{|c|c|c|c|c|c|}
\hline & Criteria & Affected Area & $\begin{array}{l}\text { Prio: } \\
\text { rity * }\end{array}$ & $\begin{array}{l}\text { Current } \\
\text { Evaluation"* }\end{array}$ & $\begin{array}{l}\text { Potential for } \\
\text { improvements }\end{array}$ \\
\hline \multicolumn{6}{|c|}{ 1. Critical Success Factors for the E-Learning Offering } \\
\hline 1.1 & Definition of Learning Contents and Media & E-Learning offering & 1 & $\operatorname{man}$ & later \\
\hline 1.2 & Selection of the Learning Management System and the Learning Environment & E-Learning offering & 1 & mant & later \\
\hline 1.3 & Realisation of a Business Model, Marketing and & E-Learning offering & 1 & חהח & later \\
\hline 1.4 & Reusability of Learning Contents & E-Learning offering & 3 & $\operatorname{mata}$ & currently existing \\
\hline \multicolumn{6}{|c|}{ 2. General Success Factors of Processes } \\
\hline 2.1 & Quality Assurance of the Output and the Offering & Complete Process & 2 & $\operatorname{lng}$ & currently existing \\
\hline 2.2 & Costs of Production, Maintenance and Development of the Output & Complete Process & 2 & ח & currently existing \\
\hline 2.3 & Reduction of process duration for Content Production & Complete Process & 3 & $\operatorname{mata}$ & currently existing \\
\hline 2.4 & Ability to measure and evaluate the Processes & Complete Process & 2 & 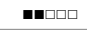 & currently existing \\
\hline 2.5 & High flexibility of the Production Processes in the case of changes in Requirements & Complete Process & 3 & 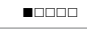 & currently existing \\
\hline \multicolumn{6}{|c|}{ 3. Prozess specific Success Factors } \\
\hline 3.1 & Reduction of Complexity & Functions & 3 & $\operatorname{man}$ & later \\
\hline 3.2 & Compliance with existing E- Learning Specifications and Standards & Functions, Process Output & 1 & वप्षप्र & currently existing \\
\hline 3.3 & Easy changes and adaptation of the produced Contents & Process Output & 3 & $\operatorname{maga}$ & currently existing \\
\hline 3.4 & Definition of Roles (Task Descriptions ) & Organizational Units & 1 & -10ma & later \\
\hline 3.5 & High degree of Automation & IT Systems & 3 & 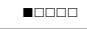 & currently existing \\
\hline 3.6 & Reduction of employed Tools & IT Systems & 1 & $\cdot$ & later \\
\hline 3.7 & Introduction of Task Descriptions, Checkilists, Schedules, or Styleguides & Information Objects & 3 & man & currently existing \\
\hline 3.8 & Reduction of content - related redundancies & Information objects & 1 & $\operatorname{anam}$ & later \\
\hline 3.9 & Avoidance of File Redundancies and inconsistent Data Storage & Information objects & 2 & 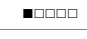 & currently existing \\
\hline 3.10 & Introduction of Versioning Control & Information objects & 3 & $\operatorname{man}$ & later \\
\hline 3.11 & Introduction of a system or a structure for Document Storage & Information objects & 3 & $\operatorname{man}$ & later \\
\hline
\end{tabular}

Table 1: Requirements catalogue for efficiency analysis of E-Learning production processes

In the succeeding stage of the reengineering project - the process evaluation - the following three potentials have been identified and selected to improve the existing situation:

- Compliance to E-Learning standards and specifications to enable conform and sustainable Learning Objects, structures, and processes (criteria 1.4, 3.2),

- Improved process automation to increase the efficiency of the processes (criteria $2.2,2.3,2.5,3.3,3.5,3.9)$,

- Standardised processes with process descriptions to improve the ability to evaluate, to measure, and to assure the quality of the output (criteria 2.4, 2.1, $3.7)$.

To realise these main potentials in phase three and four of the reengineering project, an integrative procedural model, called PELO-Model has been specified, which ensures standard-compliant content production, process automation, and process standardisation. On a Macro-Layer, this model is defining special stages for the content-related and technical development of standardised and standardcompliant Learning Objects. On the Micro-Layer, operational and individually adaptable production processes are specified (section 4 illustrates the Micro-Layer 
by introducing the improved process automation using XML-based production, employed for the KM and PM modules).

Before the Macro-Layer can be introduced, the relevant E-Learning Specifications ${ }^{3}$ need to be summarised.

\section{Standard-compliant Learning Contents}

The standardised production of Learning Objects is specified in content-specific standards ${ }^{4}$ (cf. [Hor01, pp.17]). There is a variety of different initiatives and institutions involved in the definition of the following three related areas:

- Content Packaging - the relevant norms include the IMS Content Packaging Specification, the IMS Simple Sequencing Specification, the Aviation Industry CBT Committee's Course Structure File, and the ADL SCORM Content Packaging Specification,

- Content Communication - the most important specifications are the AICC Computer Managed Instruction (CMI) and the ADL SCORM Run-Time Environment Specification, and

- Meta-Data Annotation - the relevant specifications include the IEEE Learning Object Meta-data (LOM), the IMS Learning Resource Meta-Data Specification, the SCORM Metadata Standard, the Dublin Core Meta-data, and the IMS Educational Modelling Language (EML).

There is the widespread argument, that the existing specifications are still under development and hence are not yet meeting the requirements of developers of learning offerings [Gers03, p.636]. Quite contrary, the project came to the final conclusion, that for the assessment and improvement of future standards it is inevitable to practically implement and continuously experience these de-facto standards. They already provide recognisable benefits for the content production.

The SCORM project has been regarded as the most relevant influence, as it integrated the results of various other standardisation initiatives. In the reengineering project, the available specification ADL SCORM Version $1.2^{5}$ has been analysed to identify the relevant elements for a new production process. Generally, the Sharable Content Object Reference Model (SCORM) is offering a technical

3 In fact, these standards are currently only de-facto standards, which have not yet been completely approved by the standard organizations ISO/IEC JTC1/SC36.

$4 \quad$ Next to this, there are efforts to standardise the relevant information about the learners in order to enable their system-independent transfer and to specify quality standards [CoRo02, pp.2].

5 Since January 2004, ADL SCORM version 1.3 is published [ADL04]. 
framework for web-based E-Learning. It defines the relation of course components, data models and protocols in a way, that learning contents can be exchanged between IT-systems, which employ the same model. This improves reusability, durability, interoperability, and accessibility of Learning Objects [ADL03].

The SCORM Content Aggregation Model (CAM) defines how learning resources should be structured and aggregated into an integrated learning unit, like a course. The model consists of a Content Model for the terminological description of Learning Objects, a Content Packaging definition to pack Learning Objects (to be exchanged between different Learning Management Systems), and the meta-data to describe all components.

The Content Model describes the components Asset, Sharable Content Object (SCO) and Aggregation (the whole course). Following this structural definition, the existing content components have to be structured in a tree-like hierarchy. This necessitates a working definition of what should be regarded as an Asset and what as a SCO within the concrete project. Here, the SCORM specification is not exactly defining the term Sharable Content Object. It determines only, that a SCO is the smallest possible logical learning unit, which includes at least one Asset. Assets are regarded as electronical representations, like texts, images, sounds, or web-pages. Their main property is a high degree of reusability. Next to these structural properties, there are specifications of content-related issues. For example, a SCO should be independent from the learning context, this means, it is a self-sufficient piece of learning content, which contains all required resources [LSAL03, pp.23].

Using this framework, for the KM/PM production processes a HTML-page has been defined as a SCO and its resources like for example audio- and video-based elements or non-media assets like texts and images as Assets. This structuring was done for all existing contents. If necessary for a consistent and complete content structure, some content elements, like for example abstract headings of topics were added or removed.

SCORM contains meta-data specifications with definitions of description formats to support the reusability of contents and the interoperability with other systems. This concept is already very elaborated and complete, but can also be individually extended, if necessary. Such a standardised meta-data description of Learning $\mathrm{Ob}$ jects and their interrelations is a prerequisite of modular structuring and archiving of learning contents in repositories. Prior to the actual production of the Learning Objects, a definition of employed meta-data elements (together with the definition of their concerned scope and objects) has to be generated.

The standards dealing with Content Packaging enable to store Learning Objects in a platform independent format. This implies that the KM and PM packages generated for the MBI program can also be used in other platforms than the WebCT platform, employed by the VGU. This results in less platform dependency, which 
is an important issue if for example the virtual university decides to change its basic platform in order to reduce license costs. For the learning offerings KM and $\mathrm{PM}$, the process of packaging the produced contents is supported by the open source solution RELOAD Editor developed by the British RELOAD Project [REL03].

Next to enabling a standardised form using Content Packages, the SCORM 1.2 Run-Time Environment (RTE) Specification provides the foundation for unified execution within a learning system's environment. The according elements include the Launch Mechanism, the Application Programming Interface (API), and the Data Model.

Within the SCORM Run-Time Environment, the communication between the various SCOs and the LMS is standardised. The production process has to recognise the requirements of Version 1.2 to create executable Learning Objects. The standard specifies the minimum requirements for a $\mathrm{SCO}$ to be able to communicate with the LMS. This includes the employment of the Execution State Commands LMSInitialize and LMSFinish to allow the Systems to activate and start a SCO by sending a request. The API-Adapter of the LMS invokes the SCO by sending a Javascript-based function LMSInitialize(). After finishing the interaction, the SCO sends the function LMSFinish() back to the adapter. If the channel between the LMS and the SCO is open, variables can be accessed and exchanged between the LMS and the SCO. Examples are entries about sequencing behaviours using the elements "prerequisites", "maxtimeallowed" and "timelimitaction"'.

After this brief introduction of the relevant SCORM specifications, the next section now introduces a procedural model to support the creation of reusable Learning Objects. It has been developed and tested using the existing E-Learning content production processes for the modules KM and PM.

\section{The Macro-Layer of the Procedural Model}

Using the results of the process definition and the specifications of the SCORM initiative, in the project a procedural model has been developed to create a standard-compliant course consisting of reusable Learning Objects (see figure 2). The objective was to meet the according potential as stated in the analysis stage of the reengineering project (see section 1).

The procedural model has been influenced by the SCORM Best Practice Guide for Content Developers [LSAL03, pp.4] and extends and specifies it to increase its

6 Recently, in SCORM Version 1.3 ADL published the new section about sequencing and navigation (SN). It describes how SCORM-conformant content may be sequenced through a set of learner-initiated or system-initiated navigation events [ADL04]. 
practical value. It is structured into the five Macro-Layer stages Analysis, Design, Conceptual Development, Technical Development, and Test (cf. [Bol+02, pp.1, Cis03, p.14]). Each stage is consisting of various steps, which on a Micro-Layer can be further specified by concrete process models and descriptions. This two layer concept enables the adaptation of the procedural model to meet the individual requirements (compare section 2) of the different production processes employed. Thus, a practical and easily adaptable meta-model for the production of Learning Objects is introduced, which meets the requirements of the SCORM Version 1.2 specifications $^{7}$ and hence supports the Production of reusable and standard-compliant E-Learning Offerings (PELO-Model). This model is not bound to a specific product to support the production of Learning Objects, but is describing a generic procedure, which can be applied independently of the employed software. This allows content developers to utilise it for the individual definition of their production processes.
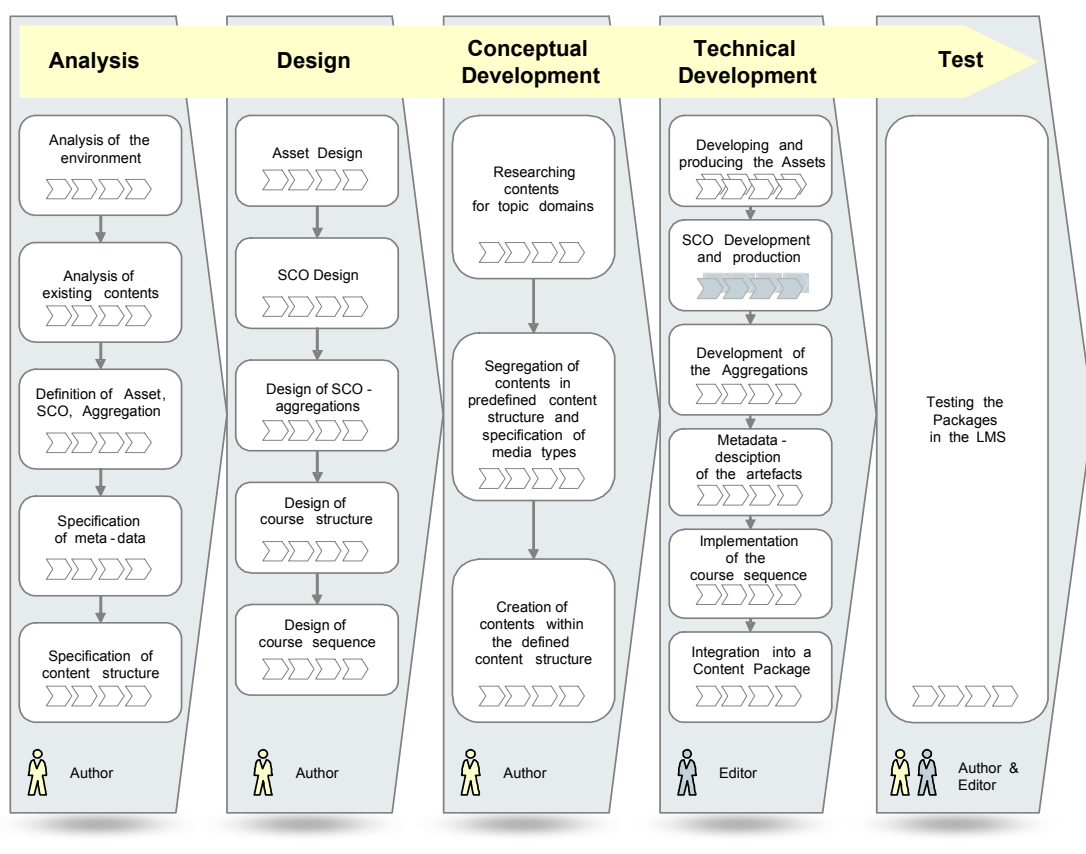

Figure 2: Procedural Model for the production of reusable and standard-compliant E-Learning Offerings (PELO-Model)

7 Currently, the PELO-Model is extended to consider the requirements of SCORM Version 1.3. 
For each of the five stages of the Macro-Layer roles $^{8}$ are made responsible. The Author role is responsible for the stages Analysis, Design, and Conceptual Development of Learning Objects, whereas the Editor role is dealing with the Technical Development of the content. For the final test of the produced contents, both roles share responsibility. The Editor is focussing on testing the technical execution and checks if all HTML-pages show their referenced objects. The Author primarily controls the course sequence, focussing on didactical issues. The various steps of the Model for the Production of reusable and standard-compliant E-Learning Offerings are now being introduced in more detail.

\subsection{Analysis}

The main objective of the Analysis Phase is to prepare the contents, like for example of the topic Knowledge Management in a way, which allows for the subsequent design of the course elements and the succeeding stages of Conceptual and Technical Development. The Analysis consists of the steps Analysis of the environment, Analysis of existing contents, Internal definition of content objects, Specification of the meta-data description, and the Specification of the content structure.

In the Analysis of the environment, the target group, the training scope, the type of training, and the place for the training are defined [Bol ${ }^{+} 02$, Section 5 pp.1]. Before that, it has to be specified, in which environment the learning units are being deployed, as often content-related changes have to be implemented to meet the needs of a special target group [LSAL03, p.25]. Examples are the depth of the content or the number of practical examples. Further preparatory questions deal with media diversity, topic depth, or the way of transmitting the contents, e.g. as a pure web-based training or as a blended learning offering [Sai02, p.39].

The Analysis of existing contents examines questions of quality, scope, and type of the information presentation [Bol+02, Section 3, pp.1]. Further it is often necessary to replace an existing hierarchical with a content-related course structure. This means existing contents need to be summarised into a topical domain to enable the modularisation of content elements. This also helps to assess if the particular topic is sufficiently explained to allow the student to achieve the course's overall learning objective.

The results of the analysis are used for the Definition of the Assets, SCOs, and Aggregations. To achieve the SCO-properties required, in the KM and PM scenario an HTML-page was considered a SCO. This HTML-page consisted of a multitude of resources defined as Assets (e.g. videos, audios, or images). The advantages of using HTML-pages as SCOs are the increased flexibility of contents,

8 To consider the project's internal premise of simplicity and efficiency, the role model has been reduced to the absolute minimum. 
the simple structuring of objects, and the unnecessary intra-SCO-sequencing ${ }^{9}$. Moreover, for the definition of the content structure it has to be considered, that a SCO must not refer to another SCO. This would disable the LMS to track the actual learning progress. In the KM and PM offerings, contents like course Course Introduction, Task Pages, or Course Summaries have also been modelled as SCOs to allow their flexible application.

For the creation of SCORM-compliant contents, the next step of Meta-data specification is optional. However, it should be employed to ensure the reusability of learning contents as this is the only way to enable search routines to easily find relevant content modules in content repositories. Within the SCORM specification, the use of meta-data has been defined for obligatory or optional application. It requires an XML-description file for every Content Package, which at least includes the obligatory meta-data elements, like for example name, meta-data scheme, format and location. In the practical KM and PM production, meta-data has only been utilised if classified as obligatory in the LOM specification and only to describe the Content Packages.

Another step of the procedural model is the Specification of content structure. In a structural diagram, all the content objects are positioned on various specified layers. For the KM and PM courses, the Course Layer has been defined as the top layer. It consists of elements like Introduction, Organisational Issues, Overview, and Unit. The Unit element contains a sub-layer, consisting of Introduction, Learning Objectives, Quick Quiz, Summary, Outlook, etc. Below this level, there is a topic layer, containing Introduction, Definition, or Example elements. These definitions allow for a consistent structuring of Learning Objects, because the meta-structure for the content types of the Learning Objects is specified [Cis03, pp.4].

\subsection{Design}

In the Design Stage, the specifications of the Analysis Stage are applied to the Assets, SCOs, and Aggregations. Moreover, all necessary design templates are produced. They build the foundation for the succeeding development of every Learning Object.

The first step is the definition and the Design of the Assets and its basic properties. This includes the identification of the Assets that actually appear in the E-Learning offering, e.g. the KM/PM project utilised GIF-, JPG-, RM-, RPM- and TXT-files. Further, in this step the exact size of each Asset, its necessary quality, and its application context are specified. In the analysed production processes, the

9 Intra-SCO-sequencing is used to indicate the sequence of learning materials if the $\mathrm{SCO}$ is being defined in a way that allows for more than one content element within one SCO. 
utilised colours have been defined as neutral as possible (grey, dark blue and white only) to avoid disadvantageous contrasts if a different LMS environment should be selected. Further, the pixel resolution, the file format of images, and the fonts' types and sizes have been specified.

In the succeeding Design of the Sharable Content Objects, the definition of the SCO (in the analysed case an HTML-page) is becoming relevant again. Thus, the audio-based HTML-page about the topic 'Architecture of a Content Management System' is comprised of Assets like an audio file with a spoken explanation, an image showing the actual CMS architecture, and an explaining text. In this step of the procedural model, the structure and the properties of the HTML-page are specified. For the Development Stage, a design template needs to be created, called 'HTML-Template-Page'. The following issues should be considered for this activity:

- If a background image is used, it should be a vector-based format. Its HTML parameters should be set to scalable instead of fixed size $[$ Bol +02 , Section 7 , p.2],

- The background colour of an HTML-page should be explicitly defined, because otherwise the colour scheme of the underlying LMS could interfere with the design palette,

- If buttons are used, they should not be positioned at a fixed location to ensure there visibility at all times [Bol+02, Section 7, p.3],

- The size of an HTML-page should not be larger than the smallest monitor size (i.e. $800 \times 600$ pixels) to ensure the visibility of the complete contents at all times.

Next to these layout definitions, the SCO has to be specified from a programmer's perspective. It has to be decided, if the Application Programming Interface of the LMS should be utilised. If the SCO is not exchanging messages via the API ('noncommunicative SCO'), there is no control possible about the learner's completion of the learning material. The KM/PM project's decision to regard a single HTMLpage as a SCO again provided the advantage, that this immanent problem has been ruled out and the employment of the API was not necessary [Jon03]. Still for testing reasons, the courses KM and PM work with communicative SCOs, which fulfil minimum requirements of communicability.

A SCO represents a self-sufficient Learning Object. Multiple SCOs can be grouped into Building Blocks, but the SCO itself can not be divided into smaller pieces. To join SCOs into a Building Block the following three issues have to be considered [Rob01]:

- The SCO must be embedded in the existing content structure,

- The course sequence, i.e. the sequence of SCOs, must be defined, and 
- The SCOs and the according description must be stored in a package.

Within the Aggregation, it is determined, which SCOs it contains. The structure diagram created in the Analysis stage contains all necessary information required for its design. Further information has already been specified in the Asset and SCO Design steps.

The next step of the Design stage is the definition and Design of the course structure. The Author puts the defined content elements Asset, SCO, and Building Block into a structure, which shows the dependencies between the objects, e.g. first layer Aggregation (i.e. Content Package), second layer SCO or Building Blocks, third layer SCO or Assets, and fourth layer Assets.

The next step of the procedural model is the Design of the course sequence. It is necessary, because the LMS controls the Inter-SCO-sequencing. The author arranges the available content objects (Assets, SCOs) in a logical sequence and thus designs the course's storyboard. For that he uses the content structure diagram. The editor applies this taxonomy to define the technical rules of the sequencing. It has to be considered, that SCOs contain no information about a time-scale or a topical sequence [Kai01, pp.58]. With the specification of a predecessor for every content object, a simple learning path can easily be created. This sequence is implemented using the variable 'prerequisites', which relates to the variable 'cmi.core.lesson_status'. This condition is hence oriented backwards, as it is defining the conditions before the SCO can be activated. The default value of the 'cmi.core.lesson_status' is 'not attempted'. If the SCO is becoming initialised, it is automatically preset to this value. When the learner uses the SCO, it can get the status 'browsed', 'incomplete', 'completed', 'failed', or 'passed'. In the KM/PM production, additional elements have been used, which don't own resources. These special elements (blocks) define the beginning of a certain topic domain (like CSCW, E-Mail, etc.). The SCORM Version 1.2 specification allows relating introductory HTML-pages to these abstract (heading-like) elements. These special HTML-pages are not regarded as common SCOs.

\subsection{Conceptual Development ${ }^{10}$}

After the theoretical definition and practical preparation of every Learning Object, the actual content is produced. This stage can not easily be unified in a procedural model, as the conceptual development is a very knowledge-intense business process, which can have multiple approaches depending on the specific scenario and resources (time, budget, persons, etc.). However, in the model some few steps indicate the minimum procedure, recommended.

10 This contribution defines the conceptual development as the content-oriented creation of Learning Objects, which are not yet in their final format. This process element can but does not need to meet the requirement of sustainability. 
In the production of contents for the KM and PM modules, the production of E-Learning contents starts just like the usual preparation of lectures using Microsoft's PowerPoint application. This allows easily exchanging and reusing learning material already prepared for classroom or virtual lectures.

Within MS PowerPoint, the Graphic Pane is used for drawing figures, the Comment Field is filled with explaining texts and the Slide Structure Navigator contains the sequence of the contents. A presentation is representing a course unit and within the MS PowerPoint based elements, graphical and textual tags are used to signal the intended implementation of special contents like video components, case studies, exercises etc. The production of the according Assets is executed in special processes (step Asset Development). As the most frequent form of presentation is an audio-based Learning Object, this special production process is now introduced in more detail.

In the Conceptual Development stage of the procedural model, the author has the task of assembling the actual contents for every Learning Object in MS PowerPoint. He usually starts with researching contents for the topic domains to be explained. The identified and selected material has to be related to slides that are positioned in a sequence which matches the definitions of the structure diagram produced in the Design Stage. He writes the explanatory text and sketches the image. Alternatively, the Author role has to decide in which form the content elements should be presented (video, case, etc.) and mark the presentation's slide accordingly. A slide show with specific formatting and tagging emerges and indicates the required technical production processes for the Editor role.

\subsection{Technical Development}

The Technical Development contains the areas Asset and SCO development, the creation of SCO-Aggregations, the definition of the course sequence, and the collection of all Learning Objects into a Content Package.

The Asset development includes the specific processes of image-, audio- and video-asset production. These segments are independent of the overall procedural model and are due to their complexity not explained within this contribution. However, in [Trie ${ }^{+} 03$ ], the KM course's special approach to cost efficient video production is explained in great detail. Further, the group currently works on improved screen-capture-videos, Flash-asset-production processes, and video-based interviews. It should be highlighted, that the intention of the PELO-model is to have a variable Macro-Layer which can be filled with specific reference processes on the Micro-Layer for the content producer to either select existing processes or to add his own individual production procedures. The step of Asset development finishes, when every required Asset is actually available in the defined form. 
Now follows the technical creation of the SCO's. In the sample case, this means that about 950 HTML-pages are being produced.

Based on the analysis of the existing production processes, the SCO development step can now be illustrated by using an example: The automation of the KM/PM production process as demanded by the second identified potential in the reengineering (see section 1). In the practical scenario this was done by introducing an XML-based data format. For this step of the Macro-Layer of the PELO-Model, the Micro-Layer processes for the KM and PM module production are being introduced in more detail in figure 3.

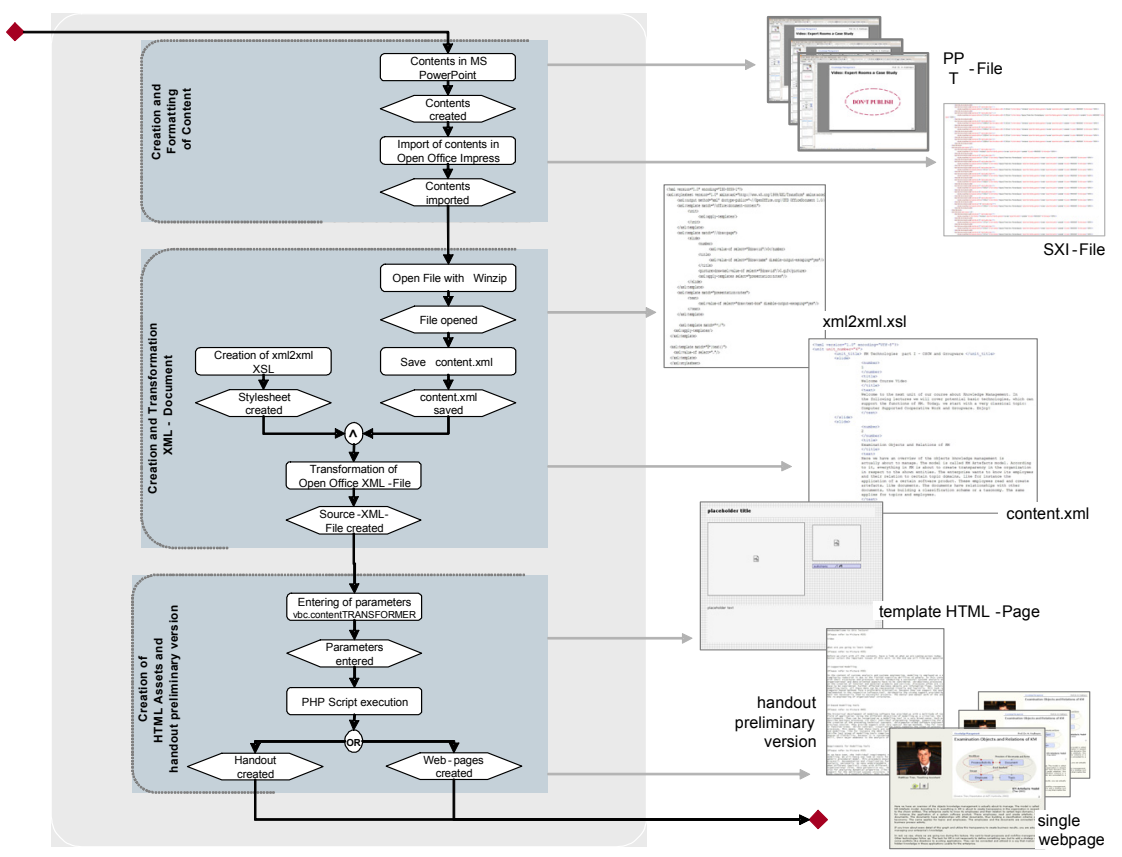

Figure 3: The KM and PM course's SCO Production Process

Originally, the learning contents are stored using the MS PowerPoint file format. As MS Office does currently not provide XML export of the presentation, OpenOffice.org 1.1.0 is utilised to import the PowerPoint document and export the contents in a special file format, which is based on the public XML-standard. This resulting JAR (JavaArchive) Format is a ZIP-file, which includes a manifest that contains a list of the content archive (cf. [Eis04]). The relevant content is located in the tag office:body. Using an XSLT transformation, a reduced and filtered $\mathrm{XML}$ file is generated to ease the subsequent automated processing.

The most important elements of an XSLT are the localisation path (pattern) and the replacement template. The localisation path has the notation xsl:template. Us- 
ing the according attribute 'match' (containing an XPath pattern), the matching content is being identified. Subsequently, the according element is instantiated and written into the output file. By using the replacement template, this output element can be individually formatted [Jec03, pp.103]. To automate this process, the Javabased XSLT-processor Xalan is utilised [Apa04]. Xalan helps to transform XMLdocuments into HTML, text, or other XML-documents. In the project, Xalan is used to generate the reduced XML file from the OpenOffice.org 1.1.0 output format. Afterwards, the XML-based contents are being automatically converted into the final HTML documents, using the individually created prototype 'vbc.contentTransformer'. This tool has been implemented in the scripting language PHP, because it is a language which can be embedded in the HTML source code (embedded code). This is then interpreted and executed on the server side. PHP furthermore owns many convenient commands for treating special variables and working with HTML contents.

After this step, the multiple SCOs of the course are available as HTML-pages. The according layout of the HTML-pages can easily be changed as the transformer tool incorporates the layout definitions and the special Javascript functions to implement the learning path.

The last steps of the Technical Development are the Meta-data description of the artefacts, the Development of the Aggregations, the Implementation of the course sequence and the assembly of all material into a Content Package. All these activities are supported by tools or instruments. Among other applications, the RELOAD Editor Software [REL03] and the MS LRN Toolkit [LRN01] have been applied and examined in terms of usability and ergonomics. Here, the advantage of employing such editing tools is that the organisation (course structure and sequence) can be changed independently of the resources and vice versa.

The RELOAD Editor Software and the LRN Toolkit are very similar as far as their basic functionality is concerned. However, the RELOAD Tool is more comfortable, as it allows for a faster Aggregation of contents and a faster annotation of meta-data. Both editors support the ADL SCORM Version 1.2 specification and thereby allow the application of the AICC CMI Data Model.

These tools have been employed in the KM/PM production processes to import the resources, create the meta-data, and define the Building Blocks. By connecting the various SCOs within these blocks, the course sequence can be specified.

\subsection{Test}

In the final Test Phase, the Content Package has to be assessed in the specific learning environment (i.e. LMS). As already introduced, the Author role is testing the content and its sequence and the Editor role checks if the technical development works correctly. 
Here, an interesting test was conducted in the reengineering project, which strongly affected the selection of the editing tool. The content-oriented and structurally defined course has been tested as a Content Package in the tools' RunTime-Environments RELOAD SCORM Player and LRN Viewer. The objective was to check the messaging behaviour and transfer of variables (using the AICC CMI Datamodel) between the SCO and its environment (usually an LMS). Both packages were complete and running. However, it has been identified, that only the Content Package produced with the LRN Toolkit could be integrated into the final Learning Environment, the VGU's WebCT platform. This required the project team to package the contents with the LRN Editor, despite the favourable results of the RELOAD Tool. The reason is that the LRN Toolkit uses the (older) IMS Content Packaging Information Model Version 1.1.2 just like the current version of $\mathrm{WebCT}^{11}$. Hence, every tool in the process chain has to be checked, if it allows for the respective standard versions.

\section{Evaluation of the Production Process}

The last step of the reengineering project required to assess the increased efficiency of the new production process. This assessment has been reduced to the measurement of the process segments that caused the most effort. The original process and the new process have been compared using their process models (EPCs). The part of comparing the amount of process segments (and the derived process activities) is now outlined to illustrate this stage of the reengineering.

A comparison of the amount of process segments of the original and the new process showed that the complexity in terms of steps could not be reduced. In the Macro-Stage Development, the original process contains seven steps (content development and formatting, creation of image-assets, creation of audio-based HTML-pages, creation of special HTML-pages, creation of Handouts, creation of glossary, and creation of the course structure in WebCT) versus eight steps for the new process (content development and formatting, creation of image-assets, development of XML-documents, development of HTML-pages (SCOs) and the raw version of the Handout, creation of glossary, finalising of the Handout, Creation of the Content Packages, and Migration into WebCT).

To extend this comparison, the time needed by the various process steps has been measured. The following evaluation only considers the part of the Learning Objects that have been changed in the new process, i.e. the step of SCO-production. Special Micro-Layer processes like video-based Asset-Production are not in-

11 Quite opposite to the RELOAD Editor, which is supporting the new version IMS Content Packaging Information Model Version 1.1.3. 
cluded. The new process is taking 72 minutes less to execute as the original production process ${ }^{12}$. This rather small improvement of 12 percent assumes that the contents are completely new and produced for the first time. However, the comparison should also take into account the time needed to change the actual content material (as an indicator of flexibility). Now, by comparing the old and new production processes of the actual HTML-pages, the new process is clearly advantageous. In the original process, the Editor role needs 106 minutes for the generation of the script and the HTML-pages. With the new process (including tools like the vbc.contentTRANSFORMER), the time needed is reduced to 34 minutes. This equals a time saving of about 70 percent. Further, it should be considered, that the generation of Learning Objects in a SCORM- or IMS-compliant format and its import into an LMS is also saving production time. The organisation of the course sequence has to be conducted only once, because the use of editing tools separates the course's organisation from the resources. Hence, if resources should need to be replaced (i.e. changing HTML-pages), the already existing course structure would automatically be imported. The initial effort is thus quite high, but afterwards changes in the content structure require only little work on the Content Package.

\section{Conclusion}

In modern and competitive E-Learning offerings, issues like sustainability and efficiency are growing in their importance. To assess the existing E-Learning production processes, this article introduced a reengineering method consisting of five phases and leading to an improved and standard-compliant structure. By examining a sub-initiative of the BMBF-project 'MBI - International Master of Business Informatics', this procedure has been illustrated. This included the application of an instrument to analyse and evaluate the existing E-Learning processes. Further, a Procedural Model to support the Production of reusable and standardcompliant E-Learning Offerings (PELO-Model) has been introduced. Its segregation into a Macro- and a Micro-Layer ensures both, a generic procedural model, which on the Macro-Layer can easily be adapted for the individual scenario, and the specification of detailed procedures on the Micro-Layer. By analysing the SCO-production process of the KM and PM E-Learning offering, it could be shown, that efficiency can be increased with the proposed method.

Future research aims at adding further Micro-processes to complete the model for more variable applications and specific guidance in the field of E-Learning content production.

12 The complete process for the production of the whole course is 600 minutes in the original structure versus 528 minutes with the new process. 


\section{References}

[ADL03] Advanced Distributed Learning: SCORM Overview. http://www.adlnet.org /index.cfm?fuseaction=scormabt, 2003, Download 2003-12-12.

[ADL04] Advanced Distributed Learning: Sharable Content Object Reference Model Version 1.3 - Sequencing \& Navigation. http://www.adlnet.org/index.cfm?fuseaction= scormabt, 2004, Download 2004-02-02.

[Apa04] The Apache Software Foundation: Xalan-Java version 2.6.0. http://xml.apache. org/xalan-j/, 2004, Download 2004-01-15.

[Bol ${ }^{+}$02] Boling, Dr. J. et al.: The SCORM Implementation Guide: A Step by Step Approach. Advanced Distributed Learning. http://www.adlnet.org/, 2002, Download 200401-04.

[Bmbf00] bmb+f: Funding Programs New Media in Education. Teaching and Learning Software. Procpect. http://www.pt-dlr.de/PT-DLR/nmb/Programm/BMBF_NEUE_ME DIEN_ENG.PDF, 2000, Download 2003-12-12.

[Cis03] Cisco Systems Inc.: Reusable Learning Object Strategy: Designing and Developing Learning Objects for Multiple Learning Approaches. White Paper. http://business.cisco. com/servletwl3/FileDownloader/iqprd/104108/104108_kbns.pdf, 2003, Download 2003-12-01.

[Cis03B] Cisco Systems Inc.: Reusable Learning Objects Authoring Guidelines: How to Build Modules, Lessons, Topic. White Paper. http://business.cisco.com/servletwl3/ FileDownloader/iqprd/104119/104119_kbns.pdf, 2003, Download 2004-02-10.

[CoRo02] Collier G., Robson R.: e-Learning Interoperability Standards. White Paper. Sun Microsystems, Inc. http://www.sun.com/products-n-solutions/edu/elearning/eLearning _ Interoperability_Standards_wp.pdf, 2002, Download 2004-02-15.

[Deg03] Degel, G.: Nachhaltigkeit von e-Learning Projekten: Erfahrungen und Erwartungen am Beispiel DaMiT (in German). http://damit.dfki.de/html/publikationen/Nachhaltigkeit.pdf, 2003, Download 2004-05-15.

[Eis04] Eisenberg, D. J.: OpenOffice.org XML Essentials. O'Reilly \& Associates. http://books.evc-cit.info/, 2004, Download 2003-11-11.

[Gers03] Gersdorf, R.: Eine Content Management-Architektur für die Umsetzung verteilter Redaktionsprozesse bei der Erstellung wieder verwendbarer Inhalte für das eLearning (in German). In: Uhr, W. et al. (Edt.) Business Informatics 2003/Volume I. PhysicaVerlag: Heidelberg, 2003, pp. 633-652.

[Gra ${ }^{+}$04] Graumann S., Neinert, F., Gräfe, B., Kahre S.: BMWA-Monitoring Informationswirtschaft (in German). http://www.bmwi.de/Navigation/Unternehmer/e-business, did=5876.html, 2004, Download 2004-05-25.

[HaHo04] Haas C., Hoppe U.: Erfolgsfaktoren für nachhaltige E-Learning-Projekte (in German). http://www.fzg.uni-vechta.de/mitarbeiter/schiewe/papers/24_haas_hoppe.pdf, 2004, Download 2004-06-15. 
[Hor01] Horton W.: Standards for E-Learning. A Consumers' Guide. William Horton Consulting. http://208.139.207.103/pdffiles/STD_01_preview.zip, 2001, Download 200402-15.

[Jec03] Jeckle M.: Vorlesung XML (in German). Lectures Notes. http://www.jeckle.de, 2003, Download 2004-01-03.

[Jon03] Jones E.: Dr. Ed's SCORM Course. Online Course. JCA Solutions, Jones Caudill \& Associates Inc. http://www.jcasolutions.com, 2001, Download 2003-09-09.

[Kai01] Kaiser R.: Analyse und Anwendung von Standards für e-Learning-Umgebungen unter besonderer Berücksichtigung des SCORM-Modells (in German). Diploma Thesis. http://cbl.fh-hagenberg.at/ links/Diplomarbeit08pdf.pdf, 2001, Download 2003-10-05.

[Kra $\left.{ }^{+} 03\right]$ Krallmann, H., Müller, C., Trier, M.: Wiederverwendbarer E-Learning Content mit ontologiegestützten Learning Content Management Systemen (in German). Unpublished Working Paper. TU Berlin. 2003.

[LRN01] Microsoft Corporation: Learning Resource iNterchange (LRN 3.0) Toolkit Solution Papers and Tutorial. Product Information. http://www.microsoft.com/technet/ itsolutions/education/toolkits/lrntoolkit/default.mspx, 2001, Download 2003-10-04.

[LSAL03] Learning Systems Architecture Lab: SCORM Best Practice Guide for Content Developers. Carnegie Mellon University. http://wwwlsal.cmu.edu/lsal/expertise/projects/developersguide/, 2003, Download 2003-12-03.

[Oest95] Österle, H.: Business Engineering: Prozess- und Systementwicklung (in German). Volume 1. Springer: Berlin et al., 1995.

[REL03] RELOAD: Reusable eLearning Object Authoring \& Delivery. http://www.reload. ac.uk/, 2004, Download 2003-10-05.

[Rob01] Robson R.: Learning Object Tutorial. Eduworks Corporation. http://www.edu works.com/LOTT/tutorial/index.html, 2001, Download 2004-01-03.

[Sai02] Sailer-Burckhardt R. et al.: IntEgrated Learning - Strategien und Vorteile für ein erfolgreiches E-Learning in der Praxis (in German). SmartBooks Publishing AG: Kösel et al., 2002.

[Saut02] Sauter C.: E-Learning- Integraler Bestandteil der zukünftigen E-Generation (in German). http://www.uni-paderborn.de/cs/kooperation/elt/vortraege/PB-ELT20020424sauter.pdf, 2002, Download 2004-01-30.

[Trie ${ }^{+}$03] Trier M., Herzog M., Krallmann H.: Der „Short-Clip“ Ansatz zur Produktion von E-Learning Video-Content für die VGU (in German). In: Uhr, W. et al. (Edt.) Business Informatics 2003/Volume I. Physica-Verlag: Heidelberg, 2003, pp.863-882.

[VGU04] Virtual Global University: School of Business Informatics. www.vg-u.de, 2004, Download 2004-05-10. 